\title{
Evaluation of Knowledge Levels of Dentistry Students on the COVID-19 and its Effects on Depression
}

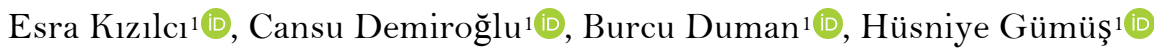

${ }^{1}$ Erciyes University, Faculty of Dentistry, Department of Pediatric Dentistry, Kayseri, Turkey.

Correspondence: Esra Kizilci, Erciyes Universitesi, Diş Hekimligi Fakültesi, Pedodonti Anabilim Dalı, 38000, Merkez/Kayseri, Turkey. E-mail: esra_ayhan85@hotmail.com

Academic Editor: Alidianne Fábia Cabral Cavalcanti

Received: 26 January 2021 / Review: 29 July 2021 / Accepted: 23 August 2021

How to cite: Kızılcı E, Demiroğlu C, Duman B, Gümüş H. Evaluation of knowledge levels of dentistry students on the COVID-19 and its effects on depression. Pesqui Bras Odontopediatria Clín Integr. 2022; 22:e210015. https://doi.org/10.1590/pboci.2022.003

\begin{abstract}
Objective: To determine the level of knowledge of dentistry students regarding the COVID-19 outbreak and to evaluate whether the risk factors of the outbreak cause depression. Material and Methods: This study was conducted with 516 dentistry students ( $3^{\text {rd }}, 4^{\text {th }}$ and $5^{\text {th }}$ grades) who started clinical practice in their education. The first part of the questionnaires applied to the students includes questions about demographic information, while the second part contains questions to determine their knowledge levels on the COVID-19 pandemic and protection against it. In the third section, Beck Depression Inventory (BDI) was used to examine depression symptoms. The data were analyzed by frequency analyses and Chi-squared tests via the IBM SPSS 22.0 software. Results: Of the 516 students, $150(29 \%)$ participants were in the $3^{\text {rd }}$, $212(41 \%)$ were in the $4^{\text {th }}$ and $154(30 \%)$ were in the $5^{\text {th }}$ grade. $355(69 \%)$ students stated that their knowledge level about COVID-19 was high. $30.9 \%$ were conscious of the importance of using masks. $29.6 \%$ were aware of the importance of using gloves, $30.3 \%$ of not shaking hands. According to BDI scores, $37.1 \%$ of the participants seemed to experience moderate to severe and very severe depression. Conclusion: It was observed that the students didn't have a sufficient level of knowledge about the factors affecting the spread of the pandemic. New stress factors such as COVID-19 may increase the incidence of depression.
\end{abstract}

Keywords: COVID-19; Coronavirus; Infection Control; Education, Dental; Students, Dental. 


\section{Introduction}

Coronavirus Disease (COVID-19) has been identified as a public health problem with serious negative effects on human health worldwide [1,2]. The disease first appeared in China and rapidly spread around the globe $[3,4]$. The mortality rate has been reported as $4.3 \%[4]$. The virus causes severe respiratory distress and is transmitted through droplet infection [3,5]. The hospital environment appears to be risky in terms of transmission since anyone can get infected through a contaminated surface or by droplets in contaminated air [5]. In addition, it has been determined that there are many resources producing aerosols caused by tools, interventions, and daily cleaning in hospitals. It has also been found that the tools used in dentistry cause aerosol in the environment, posing a risk in terms of the spread of infectious diseases or allergic reactions for patients, dentists and the staff [6]. It has been reported that the risk of aerosol is high, especially in patients with respiratory complaints [7]. Due to close contact with patients, dental clinics require extra attention against the transmission of the disease to both patients and dentists [2]. After the epidemic was declared, many dental institutions/polyclinics started to provide minimal treatment services only for emergencies, but some facilities in some affected countries still offer routine dental treatment [7].

Necessary conditions for protection from the infection are limiting intraoral radiograph imaging and $0.23 \%$ povidone-iodine mouthwash application for at least 15 seconds before dental treatment [8] and are necessitating to avoid aerosol-induced applications [3] and the use of disposable materials like rubber-drop cloth and devices $[2,9,10]$. The disease can progress asymptomatically, and the incubation period is reported to last up to 14 days $[10,11]$. The ways the disease is transmitted, not having enough information and lack of precautionary measures may cause an increase in the stress levels of dentists during treatment processes [12].

Depression is a common condition in all areas of life. It causes mental problems such as sad or anxious mood, despair, pessimism, feelings of guilt, worthlessness or helplessness, and permanent physical symptoms such as sleep and appetite disorders, headache, digestive disorders or chronic pain that do not respond to treatment [13].

Dentists and dentistry students have higher depression, anxiety or stress levels than the general population, suggesting they may be at risk for more psychological distress. Dentistry students face a challenging academic and clinical curriculum resulting in depression and anxiety [12]. They may also encounter difficult clinical conditions during their professional life.

During the pandemic, among the most at-risk groups, regarding mental stress are healthcare workers [12]. Mental stress may also be associated with fear of COVID-19 [14]. On the other hand, the anxiety level of the hospital workers with health education was lower than the hospital workers without health education [15]. Although dentistry students are theoretically educated about healthcare, it is difficult to predict how they will react to stress as they are just starting out in the field of practice.

The aim of this study is to determine the level of knowledge of dentistry students on the COVID-19 outbreak and to examine whether the risk factors of the outbreak cause depression. The study hypothesizes that the stress and depression levels of students who have just started clinical education may be affected and increased by a new stress factor, COVID-19.

\section{Material and Methods}

Ethical Clearance

Procedures were approved by the Ethical Committee of University (No: 9668-1246). 


\section{Study Design, Sample and Inclusion and Exclusion Criteria}

In the country where study was conducted, dentistry students acquire clinical education in patientbased circumstances. Clinical-based education begins in grade $3^{\text {rd }}$ grades of the undergraduate program at the Faculty of Dentistry. In this cross-sectional study, we included a total of 560 students in the $3^{\text {rd }}, 4^{\text {th }}$ and $5^{\text {th }}$ grades of the undergraduate program at the Faculty of Dentistry in 2019-2020 and who started their clinical education.

$1^{\text {st }}$ and $2^{\text {nd }}$ grades of students who did not start clinical education were excluded from the study. In addition, students who had previously received psychological treatment or use psychiatric drugs were excluded from the study considering that it will affect the mental stress state. Feedback was received from 516 of these students.

\section{Data Collection}

After consent forms were obtained, the students were asked to fill out questionnaires containing three main sections online. Sociodemographic data form: The first part of the questionnaire consisted of questions regarding the demographic information of the students (Gender, Age, Marital status, Education year, People they live with, Chronic illness, Regular drug use, Domestic/international travel). COVID-19 information form: The second part consisted of questions to determine their level of knowledge regarding COVID-19 and its prevention.

Beck Depression Inventory (BDI) form: In the last section, Beck Depression Inventory was applied. The reliability of BDI for Turkish was carried out is one of the most common forms used to measure the severity of depression [16]. Each question has four options. The scores are collected and evaluated as 1-10: minimal depression, 11-16: mild mental distress, 17-20: borderline clinical depression, 21-30: moderate depression, 31-40: severe depression, above 40: very severe depression. The psychiatrist (S.Ö.) evaluated the scores.

\section{Statistical Analysis}

Fully completed 516 questionnaires were analyzed. All analyses were performed on SPSS 22 (SPSS Inc., Chicago, IL, USA). For the normality check, the Kolmogorov-Smirnov test with Lilliefors correction was used. Descriptive analysis was made using frequency analysis. Data were given as mean \pm standard deviation or median (minimum-maximum) for continuous variables and frequency (percentage) for categorical variables. The quantitative data were analyzed by Chi-squared tests. $\mathrm{p}<0.05$ values were accepted as statistically significant difference.

\section{Results}

Of the 516 students participating in the study, 361 were women (70\%) and 155 were men (30\%). 98.1\% of the study group consisted of students between the ages of $20-25$, and $99 \%$ were single ( $\mathrm{n}=511) .150$ students $(29 \%)$ were in the $3^{\text {rd }}$ grade, $212(41 \%)$ were in the $4^{\text {th }}$ grade, and $154(30 \%)$ were in the $5^{\text {th }}$ grade. $5.8 \%(n=30)$ of the students stated that they received chronic or regular medication. 353 of the students stated that they lived with their families, 162 lived alone, and 147 shared a flat with their friends. 490 students stated that they have not contacted a family member or patient who traveled abroad in the last month, and 511 did not travel abroad in the last month. However, it was observed that $287(n=55.6)$ students traveled domestically within 1 month after the diagnosis of the first case in the country. Dental students' knowledge about the ways of transmission of the disease and preventive measures are given in Table 1. 
Table 1. Dental students' knowledge about the ways of transmission of the disease and preventive measures.

\begin{tabular}{|c|c|c|c|}
\hline Variables & Categories & $\mathbf{N}$ & $\%$ \\
\hline \multirow[t]{2}{*}{ Wear a mask } & Yes & 122 & 30.9 \\
\hline & No & 394 & 69.1 \\
\hline \multirow[t]{2}{*}{ Wear gloves } & Yes & 117 & 29.6 \\
\hline & No & 395 & 70.4 \\
\hline \multirow[t]{2}{*}{ Washing their hands } & Yes & 130 & 33.6 \\
\hline & No & 386 & 66.4 \\
\hline \multirow[t]{2}{*}{ Wet wipes } & Yes & 13 & 2.5 \\
\hline & No & 503 & 97.5 \\
\hline \multirow[t]{2}{*}{ Not shaking hands } & Yes & 120 & 30.3 \\
\hline & No & 396 & 69.7 \\
\hline \multirow[t]{2}{*}{ Kissing cheeks } & Yes & 37 & 7.7 \\
\hline & No & 479 & 92.3 \\
\hline \multirow[t]{2}{*}{ Not being in crowded environments } & Yes & 22 & 4.3 \\
\hline & No & 494 & 95.7 \\
\hline \multirow[t]{2}{*}{ Ventilation of the environment } & Yes & 30 & 5.8 \\
\hline & No & 486 & 94.2 \\
\hline Total & & 516 & 100.0 \\
\hline
\end{tabular}

To the question "How would you rate your level of knowledge about COVID-19?", 269 (52.1\%) students answered as "I have information about almost everything", 86 (16.7\%) answered as "I have full knowledge of the subject", 1 (0.2\%) said "I have no knowledge", and 13 (2.5\%) answered as "I am more or less knowledgeable." The sources of knowledge on the subject stated by the students are given in Figure 1.

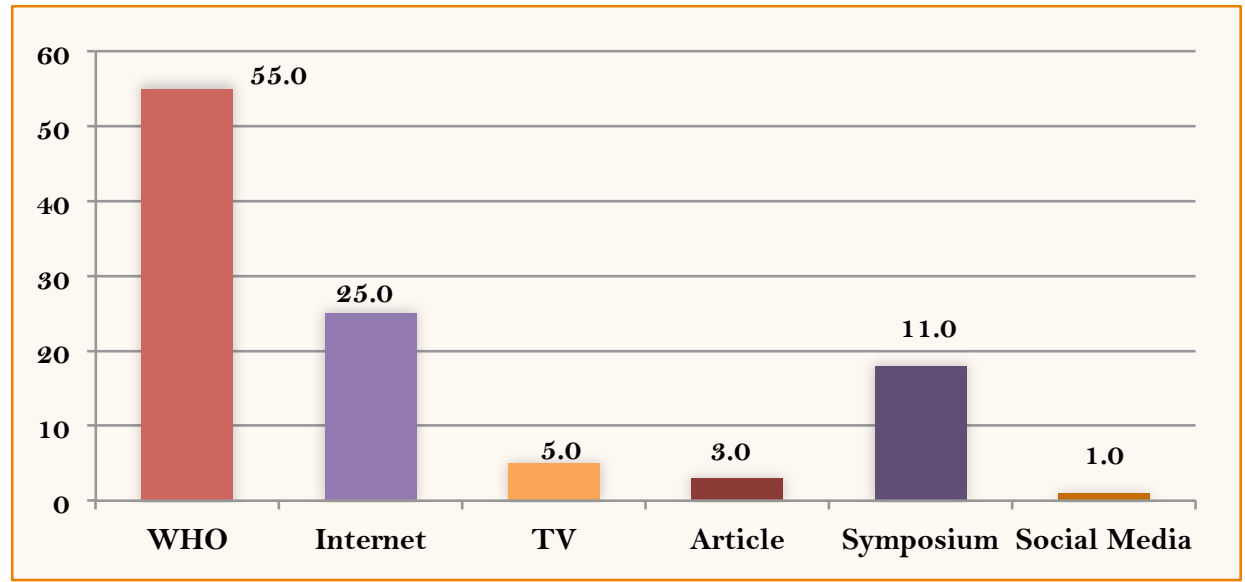

Figure 1. The sources of knowledge on the subject stated by the students.

A total of $83.9 \%$ of the students $(n=433)$ answered as "yes" to the question "Do you have access to online education at your location?" and 63.2\% (n=326) answered as "no" to the question "Has online education started in your educational institution?". 453 students $(87.8 \%)$ stated that the possibility of online education for their applied courses or internships gave them anxiety. 117 students stated that the transition to online education gave them severe anxiety, and 244 stated that they experienced very severe anxiety. The most important source of anxiety ( $\mathrm{n}=251$ ) was marked as "To begin working late due to late graduation", followed by "Increased financial dependency on the family" $(n=126) .390$ (75.6\%) participants stated that they had deteriorated sleep or nightmares during the last month. $20.7 \%(\mathrm{n}=107)$ of the students received professional psychological support, 30.6\% $(\mathrm{n}=158)$ received psychopharmacological support, and $14.9 \%(\mathrm{n}=77)$ received both psychological and psychopharmacological support. $33.7 \%(n=174)$ said that they did not receive 
psychological or psychopharmacological support. The depression classification of the students based on BDI is given in Figure 2.

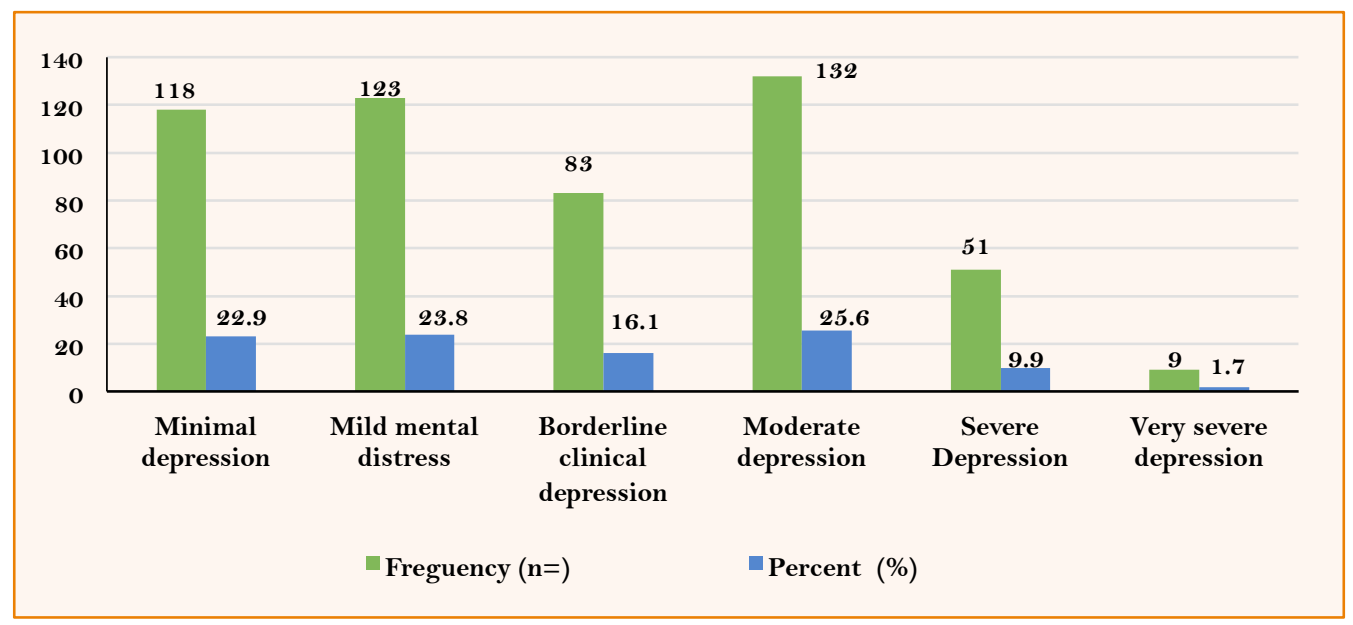

Figure 2. The depression classification of the students (frequency and percent) based on Beck Depression Inventory.

The depression classification based on gender is given in Table 2. When the groups with moderate, severe and very severe depression were evaluated in terms of gender, 149 females and 43 males were affected. In addition, there was a statistically significant difference between the groups regarding BDI scores $(p=0.04)$.

Table 2. The depression classification of the students based on gender.

\begin{tabular}{|c|c|c|c|c|c|c|c|}
\hline \multicolumn{8}{|c|}{ The Depression Classification } \\
\hline Gender & $\begin{array}{l}\text { Minimal } \\
\text { Depression } \\
\mathrm{N}\end{array}$ & $\begin{array}{c}\text { Mild Mental } \\
\text { Distress } \\
\text { N }\end{array}$ & $\begin{array}{c}\text { Borderline Clinical } \\
\text { Depression } \\
\mathrm{N}\end{array}$ & $\begin{array}{l}\text { Moderate } \\
\text { Depression } \\
\text { N }\end{array}$ & $\begin{array}{c}\text { Severe } \\
\text { Depression } \\
\mathrm{N}\end{array}$ & $\begin{array}{c}\text { Very Severe } \\
\text { Depression } \\
\mathrm{N}\end{array}$ & Total \\
\hline Girl & 66 & 87 & 59 & 104 & 39 & 6 & 361 \\
\hline Boy & 52 & 36 & 24 & 28 & 12 & 3 & 155 \\
\hline Total & 118 & 123 & 83 & 132 & 51 & 9 & 516 \\
\hline
\end{tabular}

The depression classification of the students based on grade is given in Table 3. Comparing BDI scores in terms of grades, no significant difference was found $(p=0.64)$.

Table 3. The depression classification of the students based on grade.

\begin{tabular}{|c|c|c|c|c|c|c|c|}
\hline \multirow[b]{2}{*}{ Grade } & \multirow[b]{2}{*}{$\begin{array}{c}\text { Minimal } \\
\text { Depression } \\
\mathrm{N}\end{array}$} & \multirow[b]{2}{*}{$\begin{array}{c}\text { Mild Mental } \\
\text { Distress } \\
\text { N }\end{array}$} & \multicolumn{2}{|c|}{ The Depression Classification } & \multirow[b]{2}{*}{$\begin{array}{c}\text { Severe } \\
\text { Depression } \\
\mathrm{N}\end{array}$} & \multirow[b]{2}{*}{$\begin{array}{c}\text { Very Severe } \\
\text { Depression } \\
\text { N }\end{array}$} & \multirow[b]{2}{*}{$\begin{array}{c}\text { Total } \\
\text { N }\end{array}$} \\
\hline & & & $\begin{array}{c}\text { Borderline Clinical } \\
\text { Depression } \\
\mathrm{N}\end{array}$ & $\begin{array}{c}\text { Moderate } \\
\text { Depression } \\
\mathrm{N}\end{array}$ & & & \\
\hline $3^{\text {rd }}$ & 36 & 34 & 30 & 35 & 14 & 1 & 150 \\
\hline $4^{\text {th }}$ & 46 & 45 & 32 & 60 & 24 & 5 & 212 \\
\hline $5^{\text {th }}$ & 36 & 44 & 21 & 37 & 13 & 3 & 154 \\
\hline Total & 118 & 123 & 83 & 132 & 51 & 9 & 516 \\
\hline
\end{tabular}

BDI scores among those sharing the same house or dormitory with healthcare workers were statistically higher than those who did not $(p=0.025)$. There was no significant difference between those with and without chronic or regular medication in terms of BDI scores $(p=0.78)$. Furthermore, there was no significant difference in the group traveling abroad or domestically in the last 1 month after the first casein the 
country in terms of depression scores. In addition, no significant difference was found in the group traveling abroad in the last 1 month and who was in contact with people from their immediate environment or with a patient in terms of BDI scores $(p>0.05)$.

\section{Discussion}

The dentistry profession is stressful, and dental students are not supposed to be an exception. During their clinical years, students often experience additional stress while learning clinical procedures, dealing with patients and applied procedures. This study aimed to determine the depression status in students related to COVID-19 infection and to examine their knowledge levels about infection prevention.

A study conducted in Jordan examined the awareness, perception and attitudes of 368 dentists regarding COVID-19 and infection control. It was reported that most dentists were aware of the symptoms of COVID-19 and could explain the ways of transmission of the disease and preventive measures [17].

In the studies of Khader et al. [17], 275 (74.7\%) dentists declared that it is necessary to stay away from patients and each other and to wear a mask in the waiting room to reduce the transmission of the disease. They also emphasized the importance of washing their hands intensively before starting dental treatment $[17]$.

In the studies of Kamate et al. [1], they evaluated the knowledge, attitudes and practices of dentists about the Coronavirus Disease and determined that the dentists had significant knowledge and application levels to combat the disease. Their knowledge level was found to be related to their specialization status and the years they spent in the profession of medicine [1].

Ibrahim et al. [5] conducted a questionnaire study to determine the knowledge, attitude and practice of patients applying to dental clinics regarding cross infection and infection control. In the study, 39.5\% of the participants stated inadequate knowledge about infections and infection control, and 21.8\% had sufficient knowledge. They reported that the most common information was obtained through social media and that they would warn the dentists about the use of face masks (13.3\%) and gloves (16.4\%) during dental practice [5]. In our study, although the students stated that their knowledge level about COVID-19 was high (n=357), it was seen that they did not have sufficient information about transmission protection. Only $30.9 \%$ of the students were conscious of the importance of masks, $29.6 \%$ of the gloves, $2.5 \%$ of wet wipes, $30.3 \%$ of not shaking hands, $7 \%$ of not hugging and kissing cheeks and $22 \%$ of not being in crowded environments. As stated in the studies of Kamate et al. [1], it was seen that the level of knowledge was related to the years spent in the profession and that the students did not have sufficient experience and knowledge on the prevention of clinical protection and cross infection. We think that conducting the study when the virus was newly diagnosed in the country may have also been effective in their results.

The current study determined that the most common information was obtained from both WHO sources and from the internet, unlike the study of Ibrahim et al. [5]. This may be due to the difference of the groups evaluated. Dentistry students preferred to obtain information from professional organizations like the WHO.

Mathias et al. [18] found depression rates among dentists to be $9 \%$ in their study. They declared that their gender and specialty were related to their depression levels. It has been reported that depression is higher in female dentists [18]. Hamasha et al. [19] demonstrated gender as an important risk indicator for depression in their studies evaluating individuals with undergraduate education in health-related departments. In our study, the rate of depression was higher among female dentistry students. This result supports the 
previous studies. Although the exposed environmental conditions are the same, the difference can be explained by the effectiveness of individual factors in depression.

Stress and depression levels of dentistry students may increase with clinical applications. Due to the increased mental and emotional burnout parameters in the early stages, they become more sensitive to the development of mental disorders in later periods [20]. Burger et al. [21] showed that normal depression scores were recorded at the beginning of the first semester in dentistry students, and the depression status became evident in every subsequent period. In the fifth period, the determined average levels were shown to be equal to indicate clinical treatment [21]. In our study, although there was no difference between the situations of depression among the grades, severe and very severe depression were mostly observed in $4^{\text {th }}$ graders. This may be due to the duration of clinical internships during this period. The frequency of depression may have decreased with increased adaptation to the clinic in the $5^{\text {th }}$ grade.

University students are at high risk for mental health problems and psychological distress. For example, in the study investigating depression, anxiety, and stress levels on Australian dentistry students; $24 \%$ of students had moderate or above depression levels and 11\% had moderate or above stress levels [12]. In a study conducted on Brazilian medical students, psychological distress and burnout levels (80\%) were extremely high [22]. One study investigated the depression prevalence and risk indicators of 398 individuals studying in health-related departments in Saudi Arabia. The study used the Beck Depression Inventory, where approximately $45 \%$ of the students reported that they experienced mild to severe depression. As a result, a significant number of undergraduate students were reported to experience depression [19].

In our study, $37.1 \%$ of the students experienced moderate to severe and very severe depression, and $16 \%$ were on the point of clinical depression. Studies have also reported different rates of depression among dentistry students. This may be due to intercultural differences. However, the high rate in our study may be resulted by the newly added stresses of COVID-19.

Mathias et al. expressed that only $15 \%$ of dentists who experienced depression received treatment, while most did not seek treatment [18]. In our study, 20.7\% of the students received professional psychological support, while $30.6 \%$ received psychopharmacological support. In addition, $14.9 \%(\mathrm{n}=77)$ stated that they received both psychological and psychopharmacological support. Unlike dentists, dental students have been found to have a higher tendency to receive treatment. Though the study conducted on students who get education in a particular region is a limitation, the study is important to revealed the knowledge and stress levels about COVID-19. Therefore, the new studies involving larger student groups are required.

\section{Conclusion}

Increased awareness of healthcare professionals about the COVID-19 pandemic has a serious role in preventing disease. Unfortunately, the knowledge levels of undergraduate students who just started clinical practice have been insufficient in terms of protection from COVID-19. Education should be given on the subject through scientific publications, mass media and seminars. Although stress and depression levels are affected by personal and environmental factors, new stress factors such as COVID-19 may increase the rates of depression.

\section{Authors' Contributions}


BD (D) https://orcid.org/0000-0001-7414-8866 Conceptualization, Methodology, Formal Analysis, Investigation and Writing - Review and

HG (D) https://orcid.org/0000-0003-4064-337X $\begin{aligned} & \text { Editing. } \\ & \text { Conceptualization, Methodology, Formal Analysis, Investigation, Data Curation, Writing - }\end{aligned}$ Review and Editing, Visualization and Supervision.

All authors declare that they contributed to critical review of intellectual content and approval of the final version to be published.

\section{Financial Support}

None.

\section{Conflict of Interest}

The authors declare no conflicts of interest.

\section{Data Availability}

The data used to support the findings of this study can be made available upon request to the corresponding author.

\section{Acknowledgments}

We gratefully acknowledge the psychiatrist S. O. for contribution to our manuscript.

\section{References}

[1] Kamate SK, Sharma S, Thakar S, Srivastava D, Sengupta K, Hadi AJ, et al. Assessing knowledge, attitudes and practices of dental practitioners regarding the COVID-19 pandemic: a multinational study. Dent Med Probl 2020; 57(1):11-7. https://doi.org/10.17219/dmp/119743

[2] Xu R, Cui B, Duan X, Zhang P, Zhou X, Yuan Q. Saliva: potential diagnostic value and transmission of 2019-nCoV. Int J Oral Sci 2020; 12(1):1 1. https://doi.org/10.1038/s41368-020-0080-Z

[3] Meng L, Hua F, Bian Z. Coronavirus Disease 2019 (COVID-19): Emerging and future challenges for dental and oral medicine. J Dent Res 2020; 99(5):481-7. https://doi.org/10.1177/0022034520932149

[4] Wang D, Hu B, Hu C, Zhu F, Liu X, Zhang J, et al. Clinical characteristics of 138 hospitalized patients with 2019 novel coronavirus-infected pneumonia in Wuhan, China. JAMA 2020; 323(11):1061-9. https://doi.org/10.1001/jama.2020.1585

[5] Ibrahim NK, Alwafi HA, Sangoof SO, Turkistani AK, Alattas BM. Cross-infection and infection control in dentistry: Knowledge, attitude and practice of patients attended dental clinics in King Abdulaziz University Hospital, Jeddah, Saudi Arabia. J Infect Public Health 2017; 10(4):438-45. https://doi.org/10.1016/j.jiph.2016.06.002

[6] Zemouri C, de Soet H, Crielaard W, Laheij A. A scoping review on bio-aerosols in healthcare and the dental environment. PloS One 2017; 12(5):e0178007. https://doi.org/10.1371/journal.pone.0178007

[7] Alharbi A, Alharbi S, Alqaidi S. Guidelines for dental care provision during the COVID-19 pandemic. Saudi Dent J 2020; 32(4):181-6. https://doi.org/10.1016/j.sdentj.2020.04.001

[8] Eggers M, Koburger-Janssen T, Eickmann M, Zorn J. In vitro bactericidal and virucidal efficacy of povidone-iodine gargle/mouthwash against respiratory and oral tract pathogens. Infect Dis Ther 2018; 7(2):249-59. https://doi.org/10.1007/s40121-018-0200-7

[9] Cochran MA, Miller CH, Sheldrake MA. The efficacy of the rubber dam as a barrier to the spread of microorganisms during dental treatment. J Am Dent Assoc 1989; 119(1):141-4. https://doi.org/10.14219/jada.archive.1989.0131

[10] World Health Organization. Clinical Management of Severe Acute Respiratory Infection When Novel Coronavirus $(\mathrm{nCoV})$ Infection is Suspected: Interim Guidance. 25 January 2020. Geneva: World Health Organization; 2020. Contract No.: WHO/nCoV/Clinical/2020.2.

[11] Bai Y, Yao L, Wei T, Tian F, Jin DY, Chen L, et al. Presumed asymptomatic carrier transmission of COVID-19. JAMA 2020; 323(14):1406-7. https://doi.org/10.1001/jama.2020.2565

[12] Stormon N, Ford PJ, Kisely S, Bartle E, Eley DS. Depression, anxiety and stress in a cohort of Australian dentistry students. Eur J Dent Educ 2019; 23(4):507-14. https://doi.org/10.1111/eje.12459

[13] American Psychiatric Association. Diagnostic and Statistical Manual of Mental Disorders. 5th. ed. Arlington: American Psychiatric Association; 2013. 20p.

[14] Karadem FB, Demirdaş A, Işık Ü, Kılıç F. Investigation of the psychiatric factors that determine the fear of COVID19 in healthcare workers and hospital staff in a university hospital in Turkey. J Community Psychol 2021; 1-13. https://doi.org/10.1002/jcop.22657

[15] Xia Y, Zhang H, Xia Y, Li H, Zhai L, Wang H. The self-psychological safety maintenance and its influencing factors of community frontline staff during COVID-19 pandemic. Medicine 2021; 100(3):e24140. https://doi.org/10.1097/MD.0000000000024140 
[16] Beck AT, Steer RA, Ball R, Ranieri W. Comparison of Beck Depression Inventories -IA and -II in psychiatric outpatients. J Pers Assess 1996; 67(3):588-97. https://doi.org/10.1207/s15327752jpa6703_13

[17] Khader Y, Al Nsour M, Al-Batayneh OB, Saadeh R, Bashier H, Alfaqih M, et al. Dentists' awareness, perception, and attitude regarding COVID-19 and infection control: cross-sectional study among Jordanian dentists. JMIR Public Health Surveill 2020; 6(2):e18798. https://doi.org/10.2 196/18798

[18] Mathias S, Koerber A, Fadavi S, Punwani I. Specialty and sex as predictors of depression in dentists. J Am Dent Assoc 2005; 136(10):1388-95. https://doi.org/10.14219/jada.archive.2005.0052

[19] Hamasha AA, Kareem YM, Alghamdi MS, Algarni MS, Alahedib KS, Alharbi FA. Risk indicators of depression among medical, dental, nursing, pharmacology, and other medical science students in Saudi Arabia. Int Rev Psychiatry 2019; 31(7-8):646-52. https://doi.org/10.1080/09540261.2019.1584095

[20] Scholz M, Neumann C, Steinmann C, Hammer CM, Schröder A, Eßel N, et al. Development and correlation of workrelated behavior and experience patterns, burnout and quality of life in medical students from their freshmanship to the first state examination. Psychother Psychosom Med Psychol 2015; 65(3-4):93-8.

https://doi.org/10.1055/s-0034-1375630

[21] Burger PHM, Neumann C, Ropohl A, Paulsen F, Scholz M. Development of depression and deterioration in quality of life in German dental medical students in preclinical semesters. Ann Anat 2016; 208:183-6. https://doi.org/10.1016/j.aanat.2016.05.011

[22] Castaldelli-Maia JM, Lewis T, Marques Dos Santos N, Picon F, Kadhum M, Farrell SM, et al. Stressors, psychological distress, and mental health problems amongst Brazilian medical students. Int Rev Psychiatry 2019; 31(7-8):603-7. https://doi.org/10.1080/09540261.2019.1669335 